\title{
RADIOLOGICAL EVALUATION OF NORMAL SAGITTAL VERTEBRAL, PELVIS AND GLOBAL SPINOPELVIC PARAMETERS IN A YOUNG ADULT TURKISH POPULATION
}

\author{
(1) Mehmet Atıf Erol Aksekili1, (1) Mehmet Asiltürk2, (1) Serhat Akçaalan², (1) Hatice Aksekili4 , (1) Hilmi Alkan², \\ (1) Pervin Demir ${ }^{3}$ \\ ${ }^{1}$ Ankara Yıldırım Beyazıt University, Ankara City Hospital, Clinic of Orthopedics and Traumatology, Ankara, Turkey \\ ${ }^{2}$ Ankara Yıldırım Beyazıt University Faculty of Medicine, Department of Orthopedics and Traumatology, Ankara, Turkey \\ ${ }^{3}$ Ankara Yıldırım Beyazıt University Faculty of Medicine, Department of Biostatistics, Ankara, Turkey \\ ${ }^{4}$ Gazi Mustafa Kemal Public Hospital, Clinic of Physical Therapy and Rehabilitation, Ankara, Turkey
}

Objective: Normal values of sagittal vertebral, pelvis and global spinopelvic parameters have been reported to vary from society to society. The aim of this study was to determine these parameters in a young adult Turkish population and to evaluate the relationship between the sagittal spinopelvic measurements. This was the first study on this subject in a Turkish population.

Materials and Methods: The study included a total of 170 subjects comprising 137 (80.6\%) males and 33 (19.4\%) females, with a mean age of $24.1 \pm 4.9$ years. Anteroposterior and lateral spine X-rays and pelvis X-rays were performed to evaluate the sagittal vertebral, pelvis and global spinopelvic parameters. Patients were classified according to the Roussouly classification system to classify normal variations of the vertebrae, pelvis and sacrum in the sagittal plane. Normal distribution of the variables was examined with the Shapiro-Wilk test. The Independent Samples t-test was used in the comparison of mean values.

Results: The mean and standard deviation values for sagittal vertical axis (SVA), spinopelvic inclination (T1Slop, T1SPi), thoracic kyphosis, lumbar lordosis (LL), pelvic tilt, pelvis incidence (PI) and sacral slope values were $2.7 \pm 3.8,13.5 \pm 7.5,-6.3 \pm 7.5,29.6 \pm 9.8,49.7 \pm 12.2,11.6 \pm 7.3,45.1 \pm 12.4$ and $36.2 \pm 8.5$, respectively. According to the Roussouly classification, $15.9 \%$ of the participants were classified as type $1,32.3 \%$ type $2,34.7 \%$ type 3 , and $17.1 \%$ type 4 . A statistically significant weak negative correlation was found between PI and T1SPi and a weak positive correlation was determined between PI and LL. No statistically significant correlation was determined between T1SPi and SVA.

Conclusion: One hundred and eighty-seven asymptomatic young adult Turkish volunteers were evaluated in terms of some pelvic angles and the physiological standard ranges of spinal parameters defining spinal balance and the ratios were determined according to the Roussouly sagittal morphological classification. The results showed a negative correlation between T1SPi and PI.

Keywords: Sagittal pelvic parameters, radiological evaluation, spine, Roussouly classification

\section{INTRODUCTION}

The Dubousset cone of economy concept illustrates the importance of spinopelvic balance to minimize the energy spent while standing and walking ${ }^{(1)}$. This is due to the harmonic relationship of the normal sagittal curves and the pelvic anatomy. Sagittal radiological evaluations of a healthy population could provide new information about normal sagittal alignment, and this information could contribute to the treatment of spine deformities.

In the evaluation of spinal curves, some authors have placed anatomic limit points on regional spinal curves. Berthonnaud et al. (2) named the point between lumbar lordosis (LL) and TK (thoracic kyphosis) at which lordosis becomes kyphosis as the "inflexion point" and defined it as a limited functional variable ${ }^{(2)}$. Based on the Berthonnaud concept of spinal segmentation, Roussouly et al. ${ }^{(3)}$ recommended the classification of common variables according to the spinopelvic (SP) curve in sagittal spinal alignment by defining the spinopelvic shape in 4 types ${ }^{(3)}$. Thus for the classification of normal variations of the vertebrae, pelvis and sacrum in the sagittal plane, the Roussouly classification is used ${ }^{(3)}$. When planning deformity treatment, in particular, taking the 4 types of variants of the Roussouly classification into consideration can provide useful information. In addition, it can be useful to make recommendations to the patients according to the sagittal anatomy of the lumbar spine. 
The aim of this study was to radiologically evaluate the sagittal pelvis, vertebral and global SP parameters in a young adult, asymptomatic Turkish population, to evaluate the relationships between the pelvic parameters and the global SP parameters and to determine variants of sagittal spinal alignment using the Roussouly classification ${ }^{(4)}$.

\section{MATERIALS AND METHODS}

Power analysis was applied to calculate the minimum number of participants for the study. The results showed that a minimum of 170 subjects was necessary to be able to provide mean 0.05 error, 95\% confidence interval (CI), standard deviation (SD) estimation 10 and at least 1.5 margins of error (total width 3). Adding $10 \%$ substitute volunteers, it was deemed necessary to examine at least 187 participants. Following the power analysis, approval for the study was granted by the Ankara Yıldırım Beyazit University Faculty of Medicine Clinical Research Ethics Committee (decision no: 54, dated: 05/03/2018).

The participants were selected from subjects applying for military service who had routine radiographs taken during the health screening. A total of 187 subjects were enrolled in the study, then a total of 17 were excluded for various reasons; inadequate axial radiograph in 10 cases, vertebral anomaly determined in 4 cases, and pelvic obliquity in 3 cases. The study was conducted between 2018-2019. Criteria for inclusion in the study were 1 ) healthy voluntary adult aged $17-40$ years, 2) no clinical or radiological spinal, pelvic, or hip pathology, 3 ) no lower limb length discrepancy, 4) no back pain, leg pain or arm pain thought to be related to the spine in the anamnesis in the anamnesis, 5) both femoral heads visible on the lateral radiograph, 6) no vertebral anomaly, 7) no contra-indication for the taking of radiographs, 8) Body mass index (BMI) $<30$.

Informed consent was obtained from all the participants. A record was made for each patient of demographic data including age, gender, height, weight and BMI.

For all the subjects, the radiographic protocol applied as a standard $90 \times 35 \mathrm{~cm}$ anteroposterior and left lateral radiograph including the whole spine from the occipital condyles to the sacrum, taken vertically at a distance of 2 metres from the radiography tube onto a single cassette. The radiographs were taken in the comfortable position described by Faro and Horton to minimise postural changes in the sagittal plane ${ }^{(5,6)}$. The subjects were instructed to stand with the knees and hips in full extension, shoulders at $90^{\circ}$ and elbows in full flexion with the hands on the shoulders.

The measurements were taken by an experienced spine surgeon using Surgimap software vn 2.2.15.5 (Surgimap; Nemaris Inc., New York,USA). Previous sagittal spinal alignment measurement studies made with Surgimap were used for reference ${ }^{(7,8)}$. This computer-assisted sagittal alignment measurement is extremely fast and sensitive, is acceptable in the determination of reference points and has inter and intra-observer reliability ${ }^{(9)}$. To evaluate the sagittal vertebral, pelvis and global SP parameters, measurements were taken of the sagittal vertical

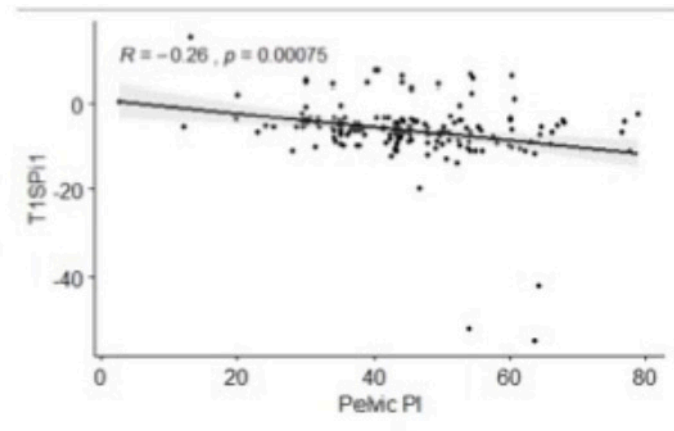

(a)

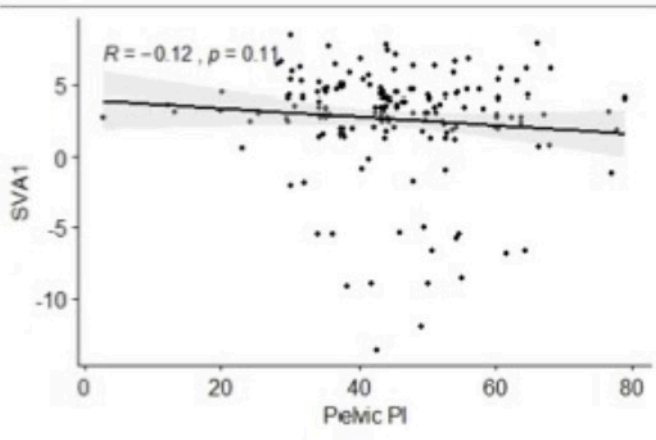

(c)

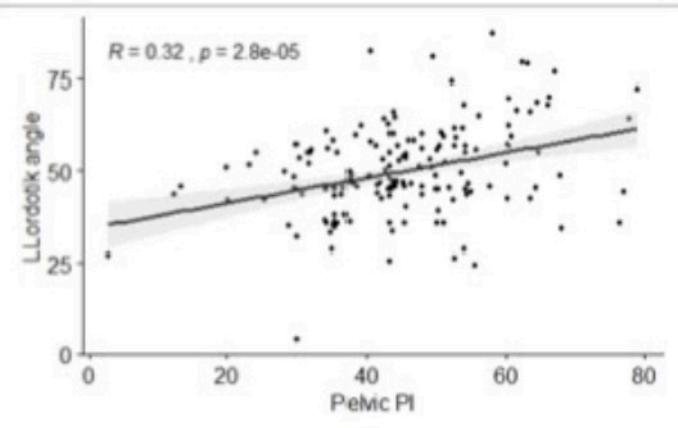

(b)

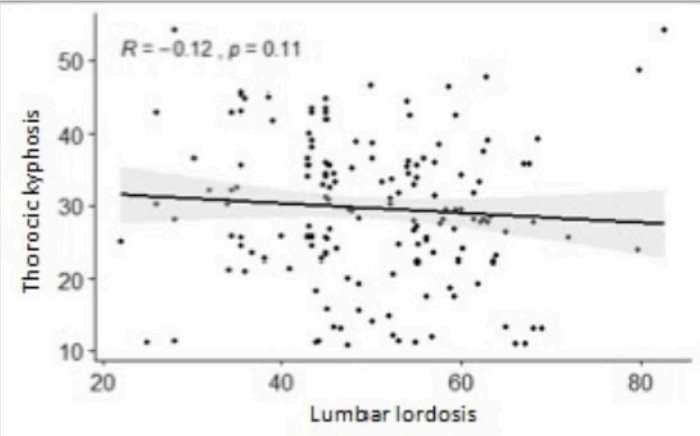

(d)

Figure 1. The measurements were made on the Surgimap software, in a; PT, PI, SS, L1-L4, PI-LL and in b; PT and PI PT: Pelvic tilt, PI: Pelvic incidence, SS: Sacral slope, LL: Lumbar lordosis, T1SPi: T1 spino pelvic inclination, SVA: Sagittal vertical axis 
turkishspine

axis (SVA), the T1 slope, T1SP inclination (T1SPi), TK, LL, pelvic tilt, sacral slope (SS), and pelvic incidence (PI) (Figure 1). Patients were classified according to the Roussouly classification system to classify normal variations of the vertebrae, pelvis and sacrum in the sagittal plane ${ }^{(3)}$. In the Roussouly classification system, type 1 and type 2 are characterized by low-grade SS and lowgrade $\mathrm{PI}$ and differ from each other by the number of lordotic vertebrae. Type 3 has high-grade SS and high-grade PI, whereas type 4 is defined as the type with the largest SS in combination with high-grade $\mathrm{PI}^{(3)}$.

\section{Statistical Analysis}

Data obtained in the study were analysed statistically using SPSS for Windows vn. 21.0 software (IBM Corpn, Armonk, NY, USA). To obtain a $95 \% \mathrm{Cl}$ in the R program, “DescTools" package was used, and "ggpubr" package in the drawing of the scatter pilot $^{(10,11)}$. Conformity of the variables to normal distribution was examined with the Shapiro-Wilks test. The Independent Samples t-test was used in the comparisons of mean values obtained from the Turkish population and mean values obtained in other studies ${ }^{(12)}$. Quantitative variables were stated as mean \pm SD, median, minimum and maximum values, and a $95 \% \mathrm{Cl}$ was used in the relationships of each pair of measurements. Categorical variables were stated as number ( $n$ ) and percentage (\%). A value of $p<0.05$ was accepted as statistically significant. Correlations between PI and LL, sagittal vertebral axis, and
T1SPi were examined with the Spearman rho correlation test. The correlation coefficients were interpreted as $0.00-0.19=$ no correlation or at a negligible level, $0.20-0.39=$ weak correlation, $0.40-0.69=$ moderate correlation, $0.70-0.89=$ strong correlation, and $0.90-1.00=$ very strong correlation ${ }^{(13)}$.

\section{RESULTS}

The 170 subjects evaluated in the study comprised 137 (80.6\%) males and 33 (19.4\%) females with a mean age of $24.1 \pm 4.9$ years (range, 17-39 years). According to the BMI classification, 5 (3.0\%) subjects were underweight (BMI $\left.<18.5 \mathrm{~kg} / \mathrm{m}^{2}\right), 132$ (77.6\%) were of normal weight and 33 (19.4\%) were overweight. The distribution of the subjects according to the Roussouly classification, is shown in Table 1.

The descriptive statistics of the variables examined in the study are shown in Table 2.

A weak negative correlation was determined between PI and T1SPi (rho $=-0.256 ; p=0.001$ ). A statistically significant weak positive correlation was determined between $\mathrm{PI}$ and $\mathrm{LL}$ $($ rho $=0.315)$ (Figure 2). No statistically significant correlation was determined between T1SPi and SVA $(p=0.830)$. There was no statistical correlation between height-weight and measured parameters.

Table 1. Distribution of the subjects in different studies according to the Roussouly classification

\begin{tabular}{lllll}
\hline Roussouly classification & Current study (\%) & Roussouly et al. ${ }^{(14)}$ & Cho $^{(15)}$ & Araujo et al.(16) \\
\hline 1 & 15.9 & 12 & 23 & 4.9 \\
\hline 2 & 32.3 & 22 & 13.1 & 31.3 \\
\hline 3 & 34.7 & 30 & 49.6 & 42.3 \\
\hline 4 & 17.1 & 20 & 14.3 & 21.5 \\
\hline
\end{tabular}

Table 2. Descriptive statistics of the variables examined

\begin{tabular}{llllll}
\hline Variables & Min; max & Median & $\begin{array}{l}95 \% \mathrm{Cl} \text { for median } \\
\text { lower limit; upper limit }\end{array}$ & Mean \pm SD & $\begin{array}{l}95 \% \mathrm{Cl} \text { for mean } \\
\text { lower limit; upper limit }\end{array}$ \\
\hline Age (years) & $17 ; 39$ & 23.0 & $22 ; 24$ & $24.1 \pm 4.9$ & $23.3 ; 24.8$ \\
\hline Height $(\mathrm{cm})$ & $153 ; 195$ & 175.0 & $174 ; 176$ & $175.1 \pm 6.8$ & $174.1 ; 176.1$ \\
\hline Weight $(\mathrm{kg})$ & $40 ; 97$ & 70.0 & $69 ; 72$ & $70.1 \pm 9.5$ & $68.7 ; 71.6$ \\
\hline BMI $\left(\mathrm{kg} / \mathrm{m}^{2}\right)$ & $17.1 ; 27.5$ & 22.7 & $22.1 ; 23.3$ & $22.8 \pm 2.2$ & $22.5 ; 23.1$ \\
\hline SVA & $-13.7 ; 8.6$ & 3.5 & $3.1 ; 4.0$ & $2.7 \pm 3.8$ & $2.1 ; 3.3$ \\
\hline T1 Slope & $-3.0 ; 40.4$ & 12.1 & $11.2 ; 13.2$ & $13.5 \pm 7.5$ & $12.4 ; 14.6$ \\
\hline TK & $10.7 ; 54.3$ & 29.3 & $27.5 ; 32.4$ & $29.6 \pm 9.8$ & $28.1 ; 31.1$ \\
\hline LL & $4.0 ; 87.2$ & 47.9 & $45.5 ; 51.2$ & $49.7 \pm 12.2$ & $47.9 ; 51.5$ \\
\hline PT & $-9.0 ; 35.3$ & 12.3 & $10.9 ; 13.4$ & $11.6 \pm 7.3$ & $10.4 ; 12.7$ \\
\hline PI & $2.7 ; 79.1$ & 43.9 & $43.2 ; 45.5$ & $45.1 \pm 12.4$ & $43.2 ; 47.0$ \\
\hline SS & $11.7 ; 62.9$ & 35.6 & $33.2 ; 38.7$ & $36.2 \pm 8.5$ & $34.9 ; 37.5$ \\
\hline T1SPi & $-55.0 ; 15.2$ & -6.0 & $-6.7 ;-5.5$ & $-6.3 \pm 7.5$ & $-7.4 ;-5.2$ \\
\hline
\end{tabular}

CI: Confidence interval, SD: Standard deviation, BMI: Body mass index, SVA: Sagittal vertical axis, TK: Thoracic kyphosis, LL: Lumbar lordosis, PT: Pelvic tilt, PI: Pelvic incidence, SS: Sacral slope, T1SPi: T1 spino pelvic inclination 


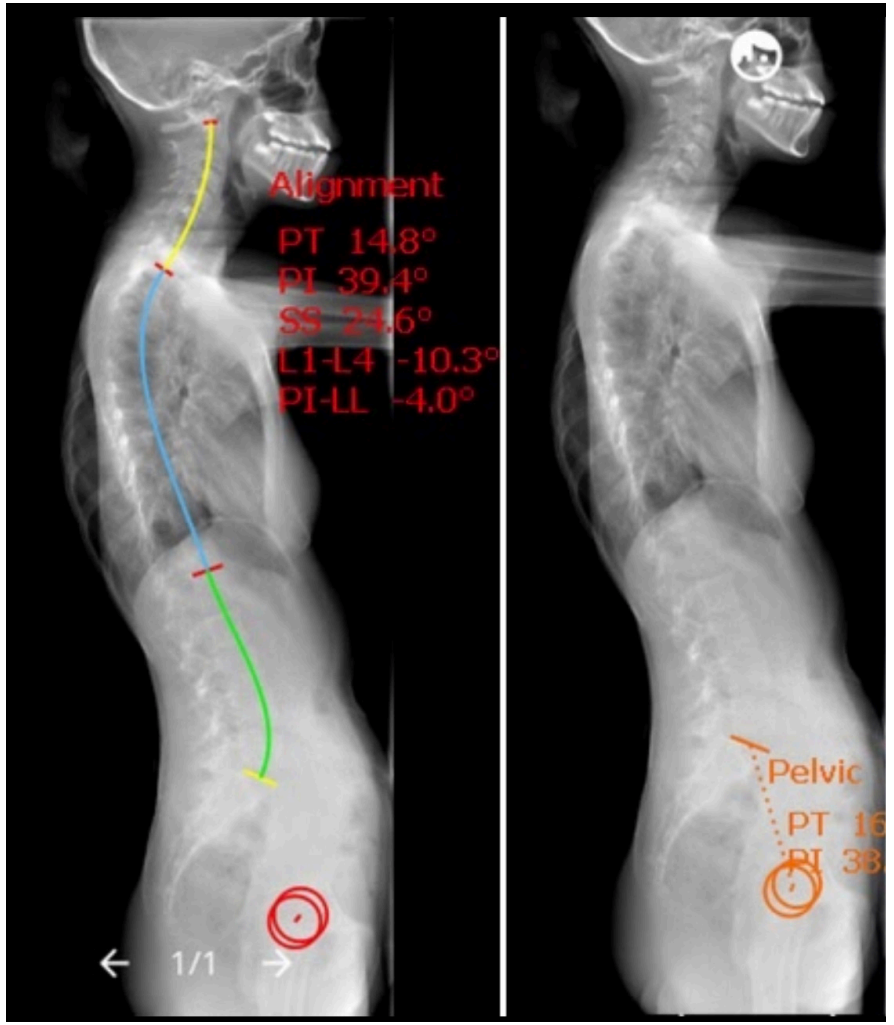

Figure 2. Scatter plot graph showing correlations between absolute PI and T1SPi, and absolute LL and SVA: a) T1SPi-absolute $\mathrm{PI} ; \mathrm{r}=0.256, \mathrm{p}<0.001$ b) LL-absolute PI; $r=0.315, p<0.001$ c) SVAabsolute $\mathrm{PI} ; \mathrm{r}=-0.125 \mathrm{p}>0.001$ d) TK-absolute LL PI; $r=-0.12$, $p=0.11$

PI: Pelvic incidence, T1SPi: T1 spino pelvic inclination, LL: Lumbar lordosis, SVA: Sagittal vertical axis, TK: Thoracic kyphosis, PT: Pelvic tilt, SS: Sacral slope

\section{DISCUSSION}

The aim of this study was to present the relationships of sagittal spinal radiographic parameters with some sagittal radiological values in a young adult Turkish population. By determining the normal distribution of these parameters, abnormal sagittal parameters will be able to be diagnosed. This is of importance as incompatibility in this plane can lead to spinal deformation and decreased quality of life. This is the first study to have presented normative sagittal radiological parameters in the Turkish population. In literature, there can be seen to be an extremely wide range of distribution of the sagittal SP parameters. This is because a great many factors affect these values. For example, in the current study subjects, the TK angle ranged from $10^{\circ}$ to $54^{\circ}$ (mean $30^{\circ}$ ), and the lordosis angle from $4^{\circ}$ to $87^{\circ}$ (mean $49^{\circ}$ ). In a study of asymptomatic subjects aged $>40$ years, Gelb et al..$^{(17)}$ reported the TK angle as mean $34^{\circ}$, and $\mathrm{LL}$ angle as means $64^{\circ(17)}$. In that study, no relationship was determined between height-weight and measured parameters, as in the current study.

Stagnara et al. ${ }^{(18)}$ found the TK angle to be mean $37^{\circ}$, and the $\mathrm{LL}$ angle to be mean $50^{\circ}$ in a study of 100 subjects in France. As the range of these values is very wide, the mean values of the normal kyphotic and lordotic curves are meaningless, and Stagnara et al. ${ }^{(18)}$ emphasised the importance of determining the normal range ${ }^{(18)}$. Factors affecting these parameters in healthy individuals include BMI, age, race, genetic and environmental factors. When the results of the current study are compared with those of other studies, it can be seen that the findings are closer to those of studies conducted on Far East Asian populations, such as in Japan, Korea and China (Figure 3).

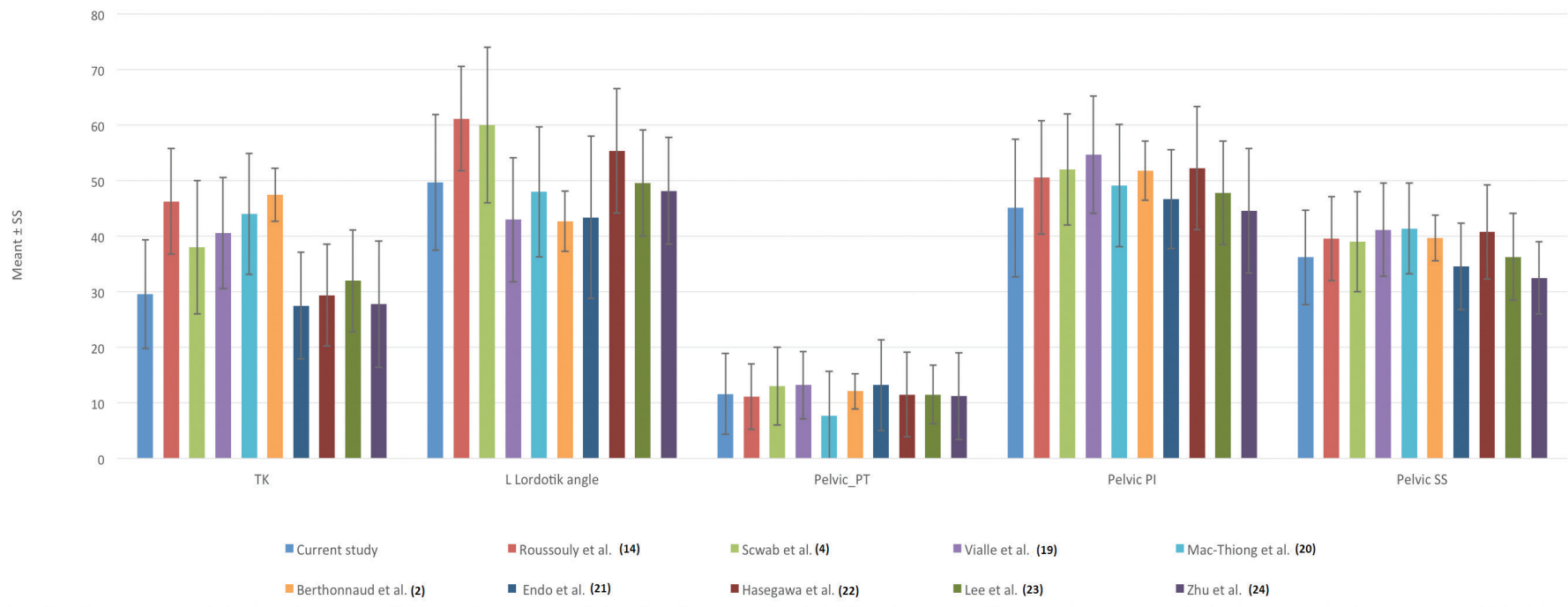

Figure 3. The mean \pm SD values of the TK, lordotic angle $(\mathrm{L}), \mathrm{PT}, \mathrm{PI}$ and SS variables obtained from the current study and previous studies. *: $p<0.05$ as a result of comparisons with the values obtained from the current study

SD: Standard deviation, TK: Thoracic kyphosis, PT: Pelvic tilt, PI: Pelvic incidence, SS: Sacral slope 
When compared with studies conducted in Europe and the USA, there can be seen to be a more significant statistical difference between sagittal parameters (Figure 2). When the TK is examined, while there was no significant difference with Asian populations, there was found to be a significant difference in the studies of European and American populations. In respect of the PI value, the current study values were closer to those of Asian populations. Although these studies were conducted on healthy individuals, the differences in demographic characteristics such as BMI, age, and male/female ratio limit the comparisons with these studies.

Common variations of lumbar sagittal alignment of the spine are classified in the Roussouly classification ${ }^{(14)}$. By refining the previously existing anatomic segmentation of L1-S1 LL, the concept of short and long LL was established ${ }^{(14)}$. The lumbar spine was separated into 4 according to the anatomic shape in the sagittal plane. Understanding the variation patterns in sagittal alignment reveals the relationship between sagittal balance and degenerative changes. It can also be important to bear in mind that there could be a need for different sagittal alignment when planning the operations necessary to recover sagittal alignment in patients with spinal pathology. In other words, it can be said that the same sagittal curve should not be given to all patients. Furthermore, specific recommendations can be made according to the LL type in patients with $\mathrm{LL}$ classified at an older age. As seen in Table 1 of the current study and other studies, the highest rate was the neutral postural position (Type 3). In the Roussouly study, it was stated that type 3 was the average spine shape, and it was not characterised by specific degeneration of the spine ${ }^{(25,26)}$. In the current study, type 3 was followed by type 2 (flat lordosis). As there is greater pressure on the discs in type 2 , this has been associated with early disc degeneration and subsequent multi-level central discopathies ${ }^{(27,28)}$.

The high pressure formed on the spine by activities and sports in individuals with type 2 LL can accelerate the discopathy mechanical process ${ }^{(27-30)}$. Therefore, even before the degenerative process develops, patients with type $2 \mathrm{LL}$ should be advised not to undertake activities which can cause pressure on the spine. In the current study, type $4 \mathrm{LL}$ was determined at the rate of $17 \%$. Type $4 \mathrm{LL}$ is known to be associated with $\mathrm{L} 5$ facet arthritis, a narrow canal and spondylolisthesis ${ }^{(27)}$. In these individuals, recommendations of isometric strengthening or flexion exercises may be of benefit in preventing spondylolisthesis ${ }^{(14)}$. Type $1 \mathrm{LL}$ was determined at the lowest rate in the current study. In this group, retrolisthesis may develop between thoracolumbar kyphosis and the LL region ${ }^{(27)}$. Facet arthrosis L5 spondylolysis may be seen in the hyperlordotic area ${ }^{(27)}$. Flexion and strengthening exercises can be recommended again for this group to prevent the development of spondylolisthesis ${ }^{(31)}$. As in several previous studies in literature, a significant positive correlation was found in the current study between LL and $\mathrm{PI}^{(26,27)}$. No significant correlation was determined between $\mathrm{PI}$ and SVA. No relationship was found between PI and SVA in a study by Endo et al. ${ }^{(21)}$ While there are some studies in the literature showing a relationship between PI and SVA, no study could be found which showed a relationship between PI and T1SPi. In the current study, a weak negative correlation was determined between PI and T1 SPi, showing global sagittal balance. T1SPi represents the angular relationship in the sagittal plane of the centre of both femoral heads with thoracic 1 spine $^{(25)}$. PI represents the angular relationship in the sagittal plane of the centre of the two femoral heads according to the sacrum and is a morphologically stable parameter ${ }^{(25)}$.

In previous studies, the T1SPi normal values have been reported as $7^{\circ}-29^{\circ}(13)$. Bakouny et al. ${ }^{(32)}$ reported these values as $-5.5^{\circ} \pm 2.6^{\circ}$. In the current study, the normal values were found to be $-6.3^{\circ} \pm 7.5^{\circ}$. As PI increases, so LL and TK together increase. There are compensation mechanisms of the pelvis shape to be able to provide global sagittal balance. Thus, the global sagittal balance can be held within a certain range ${ }^{(27,33)}$. In the current study, with the negative correlation between T1SPi and PI, it can be said that as PI increased, the global sagittal balance was compensated in a narrower range, and as PI decreased, the normal values of the sagittal balance were in a wider range. When PI decreases, the spine takes on a flatter shape in the sagittal plane, and as PI increases, the spine in the sagittal plane becomes more angular ${ }^{(14,33)}$. This can be evaluated as global sagittal balance in a wider range in a flatter spine, and a narrower range of global sagittal balance in a more angulated spine. However, there is a need for further studies to support this view.

\section{CONCLUSION}

In this study, 185 asymptomatic young adult Turkish population were evaluated in respect of some pelvic angles and the standard physiological ranges of spinal parameters defining spinal balance, and the ratios were determined of the types seen in the Roussouly sagittal morphological classification. The results showed a negative correlation between T1SPi and PI. When comparisons were made with studies of other populations, the sagittal values of the Turkish population were observed to be closer to those of Asian populations.

\section{Ethics}

Ethics Committee Approval: Approval for the study was granted by the Ankara Yıldırım Beyazıt University Faculty of Medicine Clinical Research Ethics Committee (decision no: 54, dated: 05/03/2018).

Informed Consent: Informed consent was obtained from all the participants.

Peer-review: Internally peer-reviewed.

\section{Authorship Contributions}

Concept: M.A.E.A., Design: M.A.E.A., Data Collection or Processing: M.A., S.A., HI.A., Analysis or Interpretation: M.A., HI.A., P.D., Literature Review: H.A., HI.A., Manuscript Writing: M.A.E.A., M.A. 
Conflict of Interest: No conflict of interest was declared by the authors.

Financial Disclosure: The authors declared that this study received no financial support.

\section{REFERENCES}

1. Dubousset J. Past, present, and future in pediatric spinal surgery. Ann Transl Med. 2020;8:36.

2. Berthonnaud E, Dimnet J, Roussouly P, Labelle H. Analysis of the sagittal balance of the spine and pelvis using shape and orientation parameters. J Spinal Disord Tech. 2005;18:40-7.

3. Roussouly P, Berthonnaud E, Dimnet J. Geometrical and mechanical analysis of lumbar lordosis in an asymptomatic population: proposed classification. Rev Chir Orthop Reparatrice Appar Mot. 2003;89:632-9.

4. Schwab F, Patel A, Ungar B, Farcy JP, Lafage V. Adult spinal deformitypostoperative standing imbalance: how much can you tolerate? an overview of key parameters in assessing alignment and planning corrective surgery. Spine (Phila Pa 1976). 2010;35:2224-31.

5. Faro FD, Marks MC, Pawelek I, Newton PO. Evaluation of a functional position for lateral radiograph acquisition in adolescent idiopathic scoliosis. Spine (Phila Pa 1976). 2004;29:2284-9.

6. Horton WC, Brown CW, Bridwell KH, Glassman SD, Suk SI, Cha $\mathrm{CW}$. Is there an optimal patient stance for obtaining a lateral 36" radiograph? A critical comparison of three techniques. Spine (Phila Pa 1976). 2005; 30:427-33.

7. Akbar M, Terran J, Ames CP, Lafage V, Schwab F. Use of Surgimap Spine in sagittal plane analysis, osteotomy planning, and correction calculation. Neurosurg Clin N. 2013;24:163-72.

8. Lafage R, Ferrero E, Henry JK, Challier V, Diebo B, Liabaud B, et al. Validation of a new computer-assisted tool to measure spino-pelvic parameters. Spine J. 2015;15:2493-502.

9. Vaz G, Roussouly P, Berthonnaud E, Dimnet J. Sagittal morphology and equilibrium of pelvis and spine. Eur Spine. 2002;11:80-7.

10. Kassambara A. "ggpubr: 'ggplot2' based publication ready plots. 2020. URL: https://cran.r-project.org/package $=g$ gpubr

11. Signorell A, Aho K, Alfons A, Anderegg N, Aragon T, Arachige C, et al. Tools for Descriptive Statistics. 2020. URL: https://cran.r-project.org/ package $=$ DescTools

12. Alpar R. Spor, sağlık ve eğitim bilimlerinden örneklerle uygulamalı istatistik ve geçerlik-güvenirlik. Detay Yayıncilık. 2010

13. Janssen MM, Drevelle X, Humbert L, Skalli W, Castelein RM. Differences in male and female spino-pelvic alignment in asymptomatic young adults: a three-dimensional analysis using upright low-dose digital biplanar X-rays. Spine (Phila Pa 1976). 2009;34:826-32.

14. Roussouly P, Gollogly S, Berthonnaud E, Dimnet J. Classification of the normal variation in the sagittal alignment of the human lumbar spine and pelvis in the standing position. Spine (Phila Pa 1976). 2005;30:346-53.

15. Cho Y. Evaluation of global sagittal balance in koreans adults. J Korean Neurosurg Soc. 2017;60:560-6.

16. Araújo F, Lucas R, Alegrete N, Azevedo A, Barros H. Individual and contextual characteristics as determinants of sagittal standing posture: a population-based study of adults. Spine J. 2014;14:2373-83.
17. Gelb DE, Lenke LG, Bridwell KH, Blanke K, McEnery KW. An analysis of sagittal spinal alignment in 100 asymptomatic middle and older aged volunteers. Spine (Phila Pa 1976). 1995; 20:1351-8.

18. Stagnara P, De Mauroy JC, Dran G, Gonon GP, Costanzo G, Dimnet J, et al. Reciprocal angulation of vertebral bodies in a sagittal plane: approach to references for the evaluation of kyphosis and lordosis. Spine (Phila Pa 1976). 1982;7:335-42.

19. Vialle R, Levassor N, Rillardon L, Templier A, Skalli Wafa, Guigui $P$. Radiographic Analysis of the Sagittal Alignment and Balance of the Spine in Asymptomatic Subjects. VO U M E 8.

20. Mac-Thiong J-M, Berthonnaud É, Dimar JR, Betz RR, Labelle H. Sagittal Alignment of the Spine and Pelvis During Growth: Spine.2004; 29:1642-7.

21. Endo K, Suzuki H, Nishimura H, Tanaka H, Shishido T, Yamamoto K. Caracteristics of sagittal spino-pelvic alignment in japanese young adults. Asian Spine J. 2014;8:599-604.

22. Hasegawa K, Okamoto $M$, Hatsushikano $S$, Shimoda $H$, Ono $M$, Watanabe K. Normative values of spino-pelvic sagittal alignment, balance, age, and health-related quality of life in a cohort of healthy adult subjects. Eur Spine J Off Publ Eur Spine Soc Eur Spinal Deform Soc Eur Sect Cerv Spine Res Soc.2016;25:3675-86.

23. Lee CS, Chung SS, Kang KC, Park SJ, Shin SK. Normal Patterns of Sagittal Alignment of the Spine in Young Adults Radiological Analysis in a Korean Population: Spine.2011;36:E1648-54.

24. Zhu Z, Xu L, Zhu F, Jiang L, Wang Z, Liu Z et al. Sagittal Alignment of Spine and Pelvis in Asymptomatic Adults: Norms in Chinese Populations. Spine.2014;39:E1-E6.

25. Lafage V, Schwab F, Patel A, Hawkinson N, Farcy JP. Pelvic tilt and truncal inclination: two key radiographic parameters in the setting of adults with spinal deformity. Spine (Phila Pa 1976) . 2009;34:599-606.

26. Laouissat F, Sebaaly A, Gehrchen M, Roussouly P. Classification of normal sagittal spine alignment: refounding the Roussouly classification. Eur Spine J. 2018;27:2002-11.

27. Roussouly P, Pinheiro-Franco JL. Biomechanical analysis of the spino-pelvic organization and adaptation in pathology. Eur Spine J. 2011;20(Suppl 5):609-18.

28. Tuncer C, Polat Ö, Er U. Correlation between spinopelvic parameters and the development of lumbar disc herniation. J Turk Spinal Surg. 2019;30:245-8.

29. Thoreson O, Kovac P, Sward A, Agnvall C, Todd C, Baranto A. Back pain and MRI changes in the thoraco-lumbar spine of young elite mogul skiers. Scand J Med Sci Sports. 2017;27:983-9.

30. Witwit WA, Kovac P, Sward A, Agnvall C, Todd C, Thoreson O, et al. Disc degeneration on MRI is more prevalent in young elite skiers compared to controls. Knee Surg Sports Traumatol Arthrosc. 2018;26:325-32.

31. Garet M, Reiman MP, Mathers J, Sylvain J. Nonoperative treatment in lumbar spondylolysis and spondylolisthesis: a systematic review. Sports Health. 2013;5:225-32.

32. Bakouny Z, Assi A, Massaad A, Saghbini E, Lafage V, Skalli W, et al. Roussouly's sagittal spino-pelvic morphotyp es as determinants of gait in asymptomatic adult subjects. Gait Posture. 2017; 54:27-33.

33. Been E, Pessah H, Peleg S, Kramer PA. Sacral orientation in hominin evolution. Adv Anthropol. 2013;3:133-41. 